\title{
Clinical Image:
}

\section{Large Fungus Ball and Pulmonary Embolus}

Matthew Grant, MD

\section{Case Presentation}

A 62 year-old female with severe chronic obstructive pulmonary disease and chronic Aspergillus mycetoma developed the sudden onset of dyspnea on post-operative day two after a posterior cervical spine laminectomy for severe arthritis.
This single image from her contrast-enhanced thoracic CT shows the $10 \mathrm{~cm}$ left upper lobe pulmonary fungal ball, a new extensive left lower lobe Klebsiella pneumonia, and an acute right lower lobe pulmonary embolus.

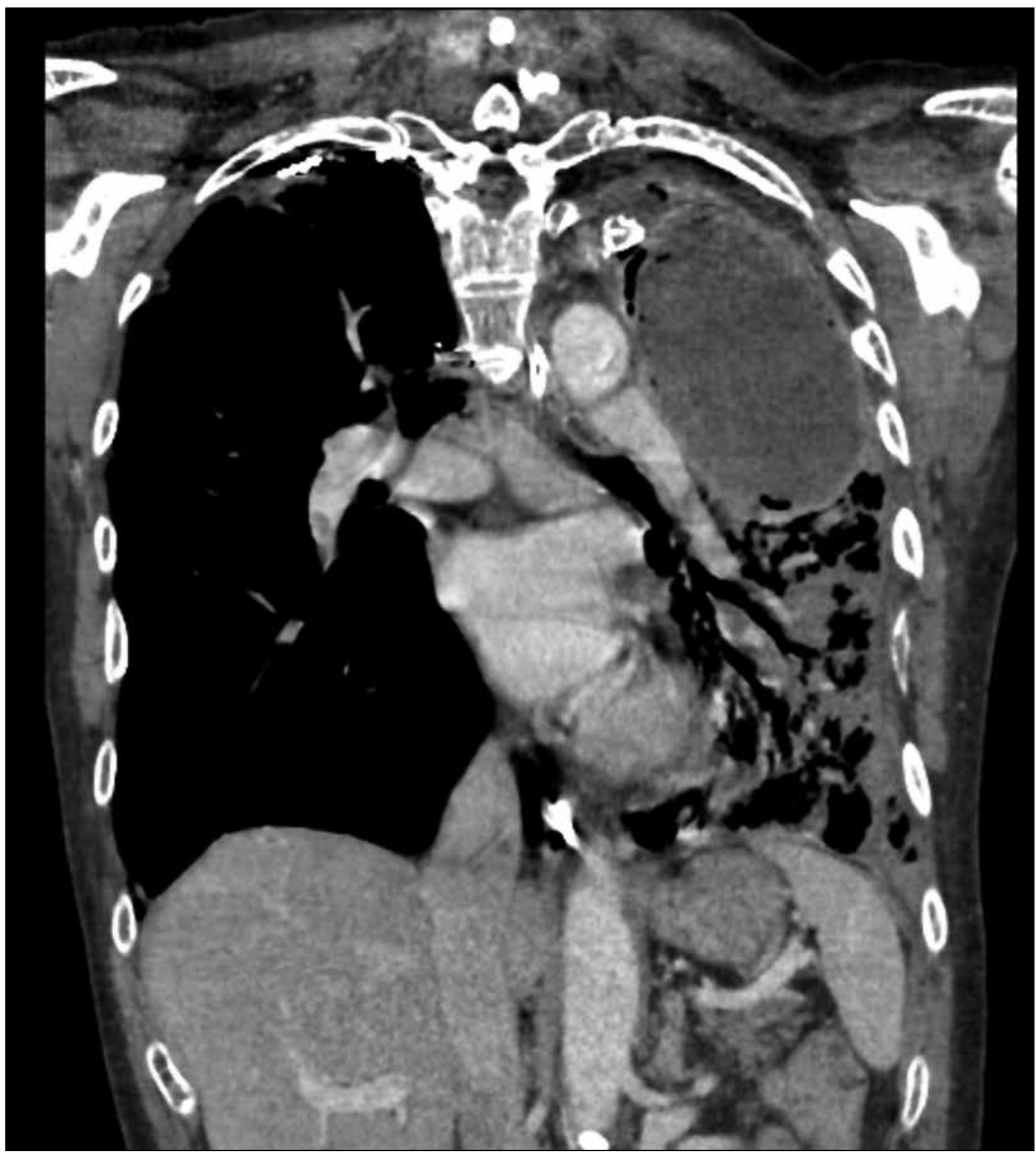

Figure 1. CT chest show large pulmonary fungus ball in the left upper lobe, left lower lobe pneumonia, and acute right lower lobe pulmonary embolus 


\section{Chinical Images: Colorectal Foreign Body}

Stephen Koczirka, MSIV, Anastasia Shnitser, MD, and Dina Halegoua-De Marzio, MD

\section{Case Presentation}

A 42 year-old male was admitted to the hospital with a known retained foreign body. A can of shaving cream was inserted into the patient's rectum several days prior to presentation. On admission, an abdominal radiograph (Figure 1) was taken to confirm the position of the foreign body and the absence of free air in the abdomen. The patient was taken to the operating room and under local anesthesia underwent successful transanal removal of the aerosol can using tenaculum forceps. There was no evidence of bowel perforation. The patient was transferred to the recovery room in stable condition.

\section{Discussion}

Insertion of foreign objects into the anus and rectum is a well described phenomenon. Anorectal objects can be inserted for sexual, medicinal or transportational purposes. They are more common in men than in women. Commonly found rectal foreign bodies may include such objects as vibrators, bottles, fruit, vegetables and toy balls. Some unusual objects reported include a light bulb, a magazine, a pair of spectacles and fish. ${ }^{1,2}$

The diagnosis of a retained foreign body should be confirmed by a plain abdominal radiograph. It will usually demonstrate a radio-opaque object; however, vegetables and rubber objects may not be visible. Low-lying foreign bodies are distal to the rectosigmoid junction while high-lying foreign bodies are above it. Objects retained within the sigmoid colon frequently require operative

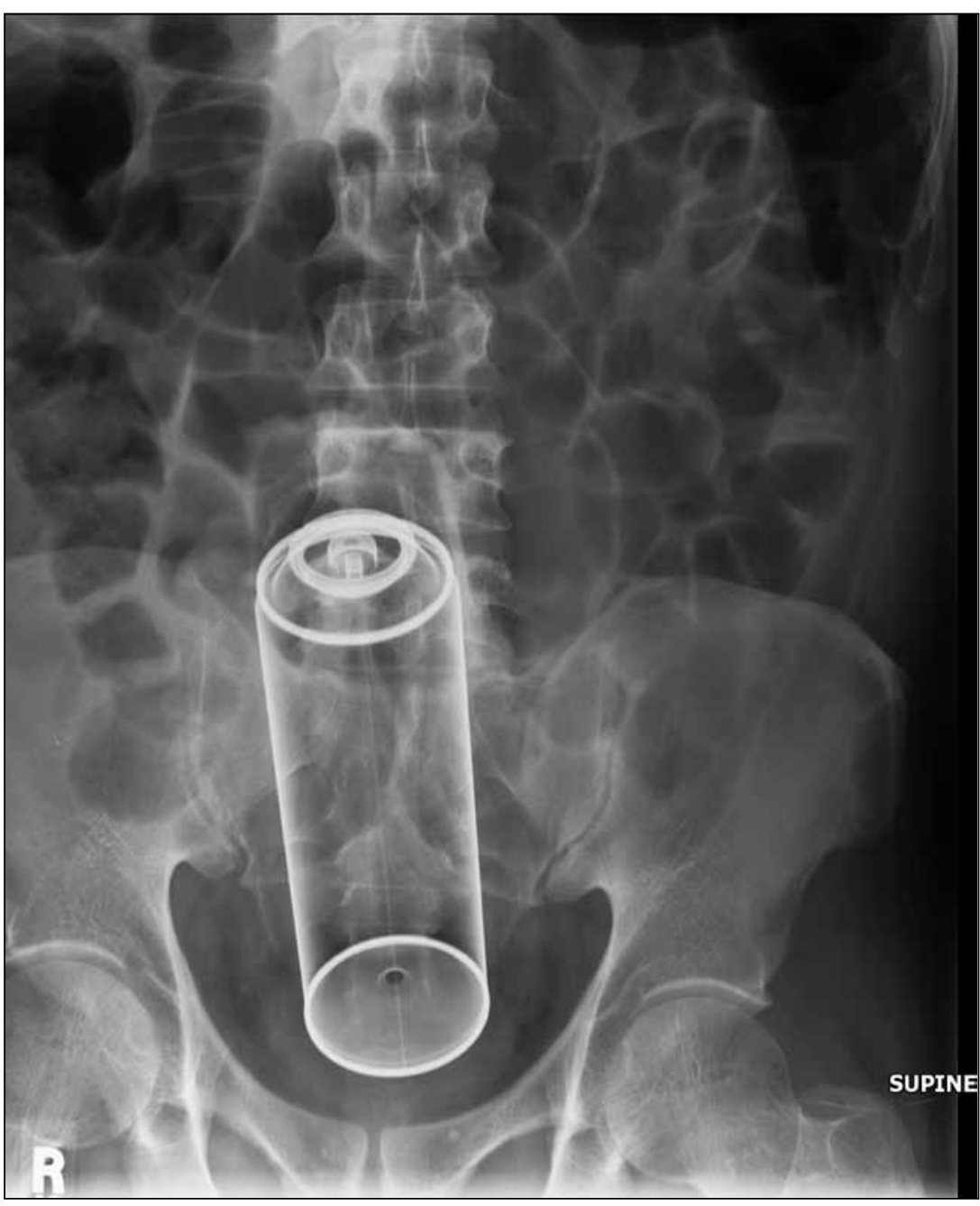

Figure 1. Abdominal radiograph showing an aerosol can within the patient's colorectum. intervention. ${ }^{3,4}$

Colorectal insertion of foreign bodies may be associated with serious injuries. Delayed removal of rectal foreign bodies can lead to severe complications, including perforation, peritonitis, sepsis, mucosal ulcerations, obstruction and bleeding. Evaluation must include a search for involvement of other structures and an evaluation of the anal sphincter. In treating these patients it is important to recognize previous attempts to remove the object prior to their presentation to the emergency department. ${ }^{2}$ After successful extraction, all patients should be observed to exclude rectal perforation. During that time, psychological support should be provided as well as education to prevent future occurrences.

\section{References}

1. Busch DB, Starling JR. Rectal foreign bodies: case reports and a comprehensive review of the world's literature. Surgery. 1986;100:512-9.

2. Rodríguez-Hermosa JI, Codina-Cazador A, Ruiz B, Sirvent JM, Roig J, Farrés R. Management of foreign bodies in the rectum. Colorectal Dis. 2007; 9:543-8.

3. Lake JP, Essani R, Petrone P. Management of retained colorectal foreign bodies: predictors of operative intervention. Dis Colon Rectum. 2004; 47:1694-8.

4. Hellinger MD.Anal trauma and foreign bodies. Surg Clin North Am. 2002; 82:1253-60. 